\title{
A MULTI-AGENT-BASED APPROACH FOR THE IMPACTS ANALYSIS OF PASSENGER FLOW ON PLATFORMS IN METRO STATIONS CONSIDERING TRAIN OPERATIONS
}

\author{
Shaokuan $\mathrm{CHEN}^{1^{*}}$, Yanan $\mathrm{ZHANG}^{2}$, Yue $\mathrm{DI}^{3}$, Fang $\mathrm{LI}^{4}$, Wenzheng $\mathrm{JIA}^{5}$ \\ ${ }^{1-4}$ The MOE Key Laboratory for Transportation Complex Systems Theory and Technology, School of Traffic and \\ Transportation, Beijing Jiaotong University, Beijing, China \\ ${ }^{5}$ China Urban Sustainable Transport Research Center, China Academy of Transportation Sciences, Beijing, China
}

Received 24 March 2016; accepted 5 April 2017

\begin{abstract}
Impacts analysis of train operation on passenger flow in metro stations is an important and fundamental requirement to improve the operational efficiency and ensure passengers a high level of service. This study aims at large metro stations where thousands of passengers are moving, boarding or alighting and the complicated interactions among passengers and between passengers and other entities like stairways or trains take place all the time. A multi-agent-based approach is developed from the investigation of movement characteristics of passengers to meet the above requirement and deal with such interactions. The simulation scenarios considering the various conditions of train operations are performed in the case studies of a metro station in Beijing (China) to prove the feasibility of the proposed approach, which is useful to formulate and evaluate the operation schemes of trains.
\end{abstract}

Keywords: metro station, passenger flow, train operation, multi-agent-based approach.

\section{Introduction}

Urban rail transit systems have been rapidly expanding in many large cities of China over the last decade due to their punctual operation, high capacity and low pollution. There have been totally 165 urban rail transit lines of $5032.7 \mathrm{~km}$ and 3234 stations operated in 34 cities of Mainland China by the end of 2017. Many urban rail transit stations in China are actually facing the severe test on how to ensure passengers moving safely and efficiently inside, especially on the platforms with limited space. For example, more than 3.7 billion passengers were served by the urban rail transit system of Beijing in 2017. There were 23 stations among 54 transfer stations in the Beijing urban rail transit network where the average amounts of transfer passengers are more than 100000 per day. Thus, the issues on passenger behaviours and evacuation in metro stations have been becoming much prevalent (Zhong et al. 2008; Shi et al. 2012), particularly when facing emergencies.

The current attentions paid to the issues relating to passengers in metro stations mainly focus on the collection and calibrations of valuable parameters and laws, formulation on passenger behaviours as well as evacua- tion strategies and their evaluation. These necessary parameters and laws usually include arrival interval distribution (Jiang et al. 2013), door open and close time (Lam et al. 1999), facilities capacity (Jiang et al. 2010; Qu, Chow 2012), boarding and alighting time (Lam et al. 1999), the relationship between velocity or flow rate and density (Fang et al. 2003; Qu, Chow 2012), etc.

With regard to modelling passenger behaviours and evacuation strategies, much fundamental research work has focused on kinetics formulation, like cellular automata (Guo 2014), social force (Helbing et al. 2005, 2006), lattice gas (Huo et al. 2014), etc. The frequently used technical methods include field surveys and analysis (Miyoshi et al. 2012), experiments and trials (Zhang, Seyfried 2014) and simulation models (Chen et al. 2012; Liu et al. 2014). A lot of investigations on evacuation strategies and evaluation in metro stations have been continuously extended after the above works. They usually emphasized evacuation time and routes (Ren et al. 2014), capacity (Zhong et al. 2008; Wu et al. 2010), measures and procedures (Shi et al. 2012) for guaranteeing that passengers are able to

${ }^{*}$ Corresponding author. E-mail: shkchen@bjtu.edu.cn 
reach safety zones efficiently, even facing emergencies (Wan et al. 2014), through calculation, simulation and intelligent methods (Shi et al. 2012).

The research efforts on the impacts analysis of train operation on passenger flow on platforms in metro stations are actually much necessary and significant for metro operators to ensure the operation of metro systems safety and efficient. They are very challenging tasks due to collecting a great amount of various field data on passenger movement, formulating the decision process of passengers and dealing with the interactions among passengers as well as between passengers and other entities in a complex spatial environment like metro stations. A simulation approach through multi-agent technique to address the impacts on passenger flow considering various train operations is proposed in this paper through implementing the operational process of interactions between passengers and trains. The case studies with different scenarios are carried out to verify the feasibility and effectiveness of the proposed method and attaining some helpful suggestions to support the work of metro operators.

\section{Impact factors of passenger flow}

The impacts on passenger flow primarily issue from the movement characteristics of passengers under the given surroundings of metro stations and operation conditions for trains. A group of quantitative indicators are introduced to evaluate the motional features of passengers on platforms and impacts from various train operations.

\subsection{Movement characteristics of passenger on platforms}

The basic attributes of passenger moving on platforms are mainly related to the arrival time, velocity and density. The selections of waiting areas and exits, boarding and alighting are much crucial behaviours of passengers when they are moving on platforms.

Arrival time distribution. The arrival of passengers to metro stations is usually considered as a continuously steady process. The passengers arrive according to a Poisson process, which is able to provide the best fit for the time interval of arrival and number of passengers. The probability of passengers arriving is calculated by Equation (1):

$$
P(N(t)=k)=\frac{(\lambda \cdot t)^{k}}{k !} e^{-\lambda \cdot t}, k=0,1,2, \ldots,
$$

where: $t$ is the rrival time [s]; $k$ is the number of passengers [person]; $\lambda$ is the rate of passengers [person/s].

Movement velocity and density. The movement velocity of passengers is closely related to their density. According to the filed investigation, the velocity is actually influenced by both longitudinal and lateral effects at the same time (Fang et al. 2003). The former effect has a logarithmic relationship with the density of passengers while the latter has a linear one. The velocity of passenger movement $v\left[\mathrm{~m} / \mathrm{s}^{2}\right]$, relating to the density of passenger flow $\rho$ [person $/ \mathrm{m}^{2}$ ] within moving area, is calculated by Equation (2):

$$
v(\rho)=v\left(\rho_{1}, \rho_{2}\right)=v_{m}(\alpha \cdot A+\beta \cdot B+\lambda),
$$

where: $\rho_{1}$ and $\rho_{2}$ are the line density in longitudinal and lateral directions respectively [person $/ \mathrm{m}] ; v_{m}$ is the velocity at which passengers can walk freely; $\alpha, \beta$ and $\lambda$ are the calibrated parameters due to longitudinal, lateral and individual effects; $A$ and $B$ are obtained according to Equations (3) and (4):

$$
\begin{gathered}
A=\frac{\ln \left(\frac{\rho_{1 m} \cdot \rho_{2}^{*}}{\rho}\right)}{\ln \left(\frac{\rho_{1 m}}{\rho_{1 c}}\right)} ; \\
B=\frac{\rho_{2 m} \cdot \rho_{1}^{*}-\rho}{\rho_{1}^{*} \cdot\left(\rho_{2 m}-\rho_{2 c}\right)},
\end{gathered}
$$

where: $\rho_{1 c}$ and $\rho_{2 c}$ are the longitudinal and lateral line densities when passengers are freely walking, $[$ person $/ \mathrm{m}] ; \rho_{1 m}$ and $\rho_{2 m}$ are the longitudinal and lateral line densities when passengers cannot move due to congestion [person $/ \mathrm{m}$ ]; $\rho_{1}^{*}$ and $\rho_{2}^{*}$ are attained by Equations (5) and (6):

$$
\begin{aligned}
\rho_{1}^{*} & =\frac{\rho_{1 c}+\rho_{1 m}}{2} ; \\
\rho_{2}^{*} & =\frac{\rho_{2 c}+\rho_{2 m}}{2} .
\end{aligned}
$$

The parameters $v_{m}, \rho_{1 c}, \rho_{2 c}, \rho_{1 m}$ and $\rho_{2 m}$ can be calculated by field data. $\alpha, \beta$ and $\lambda$ can be calibrated through multiple regression methods according to the observed values $v$ and $\rho$ from field data collections.

Area selection waiting to board trains. Passengers need to select their positions waiting to board trains when they arrive on platforms. The appropriate positions are required to board trains quickly and conveniently. The major factors to determine which area one passenger expects to be waiting at include the distance from the entrance of platforms to this area and the density there. The larger the distance and density are, the smaller the probability of position selected is. A method similar to gravity models is here used to investigate the selection probability.

The probability, which passengers coming from the platform entrance $j$ select the waiting area $i$ to board trains is calculated by Equation (7):

$$
P_{i j}=K_{i j} \frac{\left(\rho_{i \max }-\rho_{i}\right) \cdot c_{j}}{d_{i j}^{2}},
$$

where: $c_{j}$ defines the number of arrival passengers within a train interval [person/min]; $\rho_{i \max }$ indicates the permitted density of passengers within the waiting area $i$ [person $\left./ \mathrm{m}^{2}\right] ; \rho_{i}$ denotes the actual density of passengers within the area $i$ [person $\left./ \mathrm{m}^{2}\right] ; d_{i j}$ gives the distance from the area $i$ to the platform entrance $j ; K_{i j}$ is the parameter to be calibrated by the least-square method according to collected filed data. 
Exit selection after alighting from trains. Exit selection under emergency circumstances is very difficult for passengers to complete. Many factors are necessarily considered during analysing the process of evacuating from emergency events like a fire, such as the optical density and temperature of smoke and the previous use of exit (Zhang et al. 2013). The selection of exits or routes to leave in the situation of normal operation is relatively simple for the passengers alighting from trains as they usually tend to one of the nearest exits to leave.

Dwell time and number of boarding and alighting passengers. As passenger trips using metro trains increase, trains will have to spend more time at stations in order to enable the most/all of passengers to board and alight, which will lead to increased dwell times. The number of boarding and alighting passengers as well as their consuming time is closely related to the dwell time of trains. Similar to some research on the relationships (Lam et al. 1999; Chen et al. 2013), the dwell time of trains $T_{d w}$ can be well fitted using a linear function in Equation (8):

$$
T_{d w}=t_{b d} \cdot N_{b d}+t_{a l} \cdot N_{a l}+t_{o p-c l}+t_{a r r-d e p},
$$

where: $N_{b d}$ and $N_{a l}$ are the number of boarding and alighting passengers [person]; $t_{b d}$ and $t_{a l}$ are the average consuming time to board and alight a train per passenger respectively [s/person]; $t_{o p-c l}$ is the total time of door opening and closing when trains stop at stations $[s] ; t_{\text {arr-dep }}$ is the arrival and departure time of trains. These four times can be calibrated by collecting observed data.

\subsection{Train operation conditions}

Train operations greatly influence the dynamic state of passenger flow on metro platforms. When peak-hour demand temporally exceeds the maximum loading capacity of a train, passengers may not be able to board the next arrival train fully and have to wait in queues for the following trains. Some operation conditions including the headway, synchronization of arrival time and dwell time of trains will be focused on when an impact of train operations on passenger flow is investigated.

An even schedule with a constant headway between consecutive trains can reduce the total waiting time of passengers on platforms when their arrival pattern at stations follows some particular probability distributions, such as uniform and Poisson distributions (Niu, Zhou 2013). The coordination and synchronization between trains and their connecting trains can provide immediate transfer and little waiting time for passengers (Wong et al. 2008). The dwell time of trains may critically interact with the crowding condition on platforms. The interaction usually affects the behaviour of passengers and their assembling characteristics and also changes the operational capacity of metro lines (Lam et al. 1999). Appropriate combinations of the above three conditions are helpful to enhance the efficiency of transportation, alleviate the congestion on platforms and improve the overall Level Of Service (LOS).

\subsection{Evaluation indicators}

The impact extent of train operations on passenger flow is able to be evaluated through quantificational indicators. The average density, distribution equitability, movement efficiency and average queue length of passengers are employed here to assess the impacts.

Average density. The average density is one of the most common indicators to depict the LOS in metro stations. The Transit Capacity and Quality of Service Manual (National Academies of Sciences... 2013) gives a popular LOS category and recommended thresholds for passengers moving on walkways, doorways and stairways as listed within the first three columns in Table 1.

The average density $D_{p}$ to evaluate the overall congestion extent of platforms, is usually attained by Equation (9):

$$
D_{p}=\sum_{t=1}^{T} \frac{N_{t} \cdot \frac{t}{A}}{T},
$$

where: $N_{t}$ is the number of passengers in studied regions within the duration $t ; T$ and $A$ represent the total studied duration and region area respectively.

Distribution equitability. The distribution equitability describes detailed distribution situations of passengers on platforms. It is usually reflected by the temporal and spatial equitabilities as follows:

1) Temporal equitability. The temporal equitability defines the ratio of passenger density between maximum and average values within a given duration.

Table 1. LOS category for passengers flow from Transit Capacity and Quality of Service Manual

\begin{tabular}{|c|c|c|c|c|c|}
\hline \multirow{2}{*}{ LOS } & \multirow{2}{*}{ Walkways [person $/ \mathrm{m}^{2}$ ] } & \multirow{2}{*}{$\begin{array}{l}\text { Queuing and waiting area } \\
\text { [person } / \mathrm{m}^{2} \text { ] }\end{array}$} & \multirow{2}{*}{$\begin{array}{c}\text { Stairways } \\
{\left[\text { person } / \mathrm{m}^{2} \text { ] }\right.}\end{array}$} & \multicolumn{2}{|c|}{ Efficiency of occupants } \\
\hline & & & & Average speed $[\mathrm{m} / \mathrm{s}]$ & Degree of efficiency \\
\hline $\mathrm{A}$ & $<0.3$ & $<0.83$ & $<0.53$ & $>1.32$ & $0 \ldots 0.209$ \\
\hline B & $0.3 \ldots 0.43$ & $0.83 \ldots 1.1$ & $0.53 \ldots 0.71$ & $1.27 \ldots 1.32$ & $0.209 \ldots 0.235$ \\
\hline $\mathrm{C}$ & $0.43 \ldots 0.71$ & $1.1 \ldots 1.43$ & $0.71 \ldots 1.1$ & $1.22 \ldots 1.27$ & $0.235 \ldots 0.265$ \\
\hline $\mathrm{D}$ & $0.71 \ldots 1.1$ & $1.43 \ldots 3.3$ & $1.1 \ldots 1.43$ & $1.15 \ldots 1.22$ & $0.265 \ldots 0.307$ \\
\hline $\mathrm{E}$ & $1.1 \ldots 2.0$ & $3.3 \ldots 5.0$ & $1.43 \ldots 2.5$ & $0.77 \ldots 1.15$ & $0.307 \ldots 0.536$ \\
\hline $\mathrm{F}$ & $>2.0$ & $>5.0$ & $>2.5$ & $<0.77$ & $0.536 \ldots 1.0$ \\
\hline
\end{tabular}

(National Academies of Sciences... 2013) 
It is becoming better when the ratio is approaching 1.0 and calculated by Equation (10):

$$
E_{\text {tep }}=\frac{D_{\max }^{T}}{D_{\text {ave }}^{T}},
$$

where: $D_{\max }^{T}$ and $D_{\text {ave }}^{T}$ are the maximum and average densities of passengers emerging within the total duration $T$ respectively [person $/ \mathrm{m}^{2}$ ].

2) Spatial equitability. The spatial equitability defines the ratio of passenger density between maximum and average values over different areas. Similar to the temporal equitability, it is becoming better when the ratio is approaching 1.0 and attained by Equation (11):

$$
E_{s p t}=\frac{D_{\max }^{s p t}}{D_{\text {ave }}^{s p t}},
$$

where: $D_{\max }^{s p t}$ and $D_{\text {ave }}^{s p t}$ are the maximum and average density of passengers through different areas respectively [person $/ \mathrm{m}^{2}$ ].

Movement efficiency. All passengers have to move from entrances to boarding areas or from alighting areas to exits on metro platforms. The movement efficiency reports the mobility of passenger flow and calculated by Equation (12):

$$
E_{m}=\frac{v_{\text {free }}-v_{\text {real }}}{v_{\text {free }}},
$$

where: $v_{\text {free }}$ and $v_{\text {real }}$ are the free-flow and actual velocities $[\mathrm{m} / \mathrm{s}]$ of passengers when they are moving. $E_{m}$ varying between 0 and 1 , indicates the highest efficiency movement if it is approaching 0 , and vice versa. A recommend degrees of efficiency considering the division of LOS from Transit Capacity and Quality of Service Manual (National Academies of Sciences... 2013) are given within the last two columns in Table 2 due to the value of free-flow velocity $v_{\text {free }}=1.66 \mathrm{~m} / \mathrm{s}$.

Average queue length. The average queue length in boarding areas represents the congestion extent and operational efficiency. It is usually obtained through Equation (13):

$$
L=\sum_{t=1}^{T} \sum_{k} \frac{l_{t, k}}{T},
$$

where: $l_{t, k}$ is the number of passengers queuing in the boarding area $k$ within the duration interval $t$.

\section{Multi-agent-based simulation approach}

The impact analysis of train operation on passenger flow is a very complex issue as it is related to infrastructural environments, operation conditions and passenger movement characteristics. The interactions between passengers, environments and trains involve not only space, time and information exchange also human decision and behaviours that multi-agent-based technique is a competent approach to handle.

\subsection{Multi-agent-based technique}

The origin of agent in computer science was found during the early 90s last century. Multi-agent systems consisting of the set of agents quickly became the key issues in various areas, which many researchers have paid much attention to, especially in engineering and technology (Niazi, Hussain 2011). An agent is defined as an entity that is able to perceive environments or other entities, make decision due to given rules and take actions for specific tasks. The basic elements of a multi-agent system contain environment, sensors, knowledge base, decision rules and actuators.

Multi-agent-based technique has a lot of transportation-related applications, which have to deal with a great number of issues on coordination, communication and negotiation among subjects (travellers, vehicles, detectors etc.), such as traffic signal control (Kosonen 2003), carpooling (Galland et al. 2014) and pedestrian interactions (Liu et al. 2014).

\subsection{Construction and implementation of multi-agent model}

The interactions in metro stations customize two parts, environment and agents. The former part covers all possible entities or facilities that passengers will pass when they move in metro stations, including entrances/exits, walkways, corridors, rail tracks, stairways or escalators, walls, pillars as well as some spaces like boarding/alighting areas. The lengths and widths, positions, sizes and performances of the above entities or facilities are required to be known.

The latter mainly contains the passenger and train agents moving inside metro stations. The framework of agents system, operational process of passengers and trains as well as simulation flowchart of interactions among environment, passengers and trains are described here to construct a multi-agent model for the impact analysis from train operation on passenger flow on platforms. Moreover, the events relating to evaluation indicators are established to record the above impacts.

AnyLogic is a powerful tool that is able to provide complex solutions through multi-agent-based and system dynamics simulation to plan, manage, and evaluate pedestrian flows in public buildings like railway stations. Its pedestrian library is selected to construct the simulation environment including platforms and tracks, entities (walls, pillars, barriers, stairways and escalators etc.) and events (simulation clock and generators) and implement the movement process of passengers in metro stations.

\subsubsection{Framework of agents}

An agent usually involves three types of basic elements, perception, decision rules and actions. Moreover, the interactions among agents and between agents and entities have to be considered to describe. The passenger and train agents are further framed as follows when a multi-agent simulation model is developed. 
Passenger agents. Passenger agents simulate the characteristics and behaviour of passengers in metro stations through a process of perception, decision and action. The perception mainly comes from the information about environment, other passenger agents and train agents. The decisions are made through judging the information perceived by passenger agents in terms of the given rules for basic movement, position selection to board trains and exit selection to leave from trains before. The actions including walking, boarding and alighting, selecting boarding areas and exits as well as interacting with other agents or environment are taken after perception and decision. The knowledge bases of passengers comprising the attributes, arrival time distribution, velocity-density relationship and boarding/alighting time of passengers are also adopted here. The detailed framework of passenger agents is given in Figure 1a.

The movement process of passenger agents is addressed by the pedestrian library of AnyLogic through the social force model, which was initially proposed according to the fluid dynamics equation in 1995 (Helbing, Molnár 1995). The social force mainly contains desire force, repulsive force and attractive force with different properties
(Wan et al. 2014) as briefly shown in Equation (14):

$$
\begin{aligned}
& m_{\alpha} \cdot \frac{d \vec{\omega}_{\alpha}}{d t}=\vec{F}_{\alpha}^{0}(t)+\sum_{\beta} \vec{F}_{\alpha \beta}(t)+ \\
& \sum_{B} F_{\alpha B}(t)+\sum_{i} \vec{F}_{\alpha i}(t)+\xi
\end{aligned}
$$

where: $m_{\alpha}$ and $\vec{\omega}_{\alpha}$ are the mass and desired velocity of any passenger agent $\alpha ; \vec{F}_{\alpha}^{0}(t)$ denotes the desired force of $\alpha ; \vec{F}_{\alpha \beta}(t)$ represents the repulsive force between $\alpha$ and other agent $\beta ; \vec{F}_{\alpha B}(t)$ determines the repulsive force between $\alpha$ and a barrier $B ; \vec{F}_{\alpha i}(t)$ indicates the attractive force between $\alpha$ and other agent $i$ in the same attractive group; $\xi$ expresses the a fluctuation term that means random variation of agent behaviour.

Train agents. Similar to passenger agents, train agents involve the stages of perception, decision and action, which are able to reflect the process of trains approaching, dwelling at and leaving from stations. Combining the knowledge bases, which form from train attributes, movement characteristics and scheduling schemes, train agents make decisions on when and how to take actions on changing their movement states along tracks (arriving and stopping, starting and leaving), dwelling at stations,

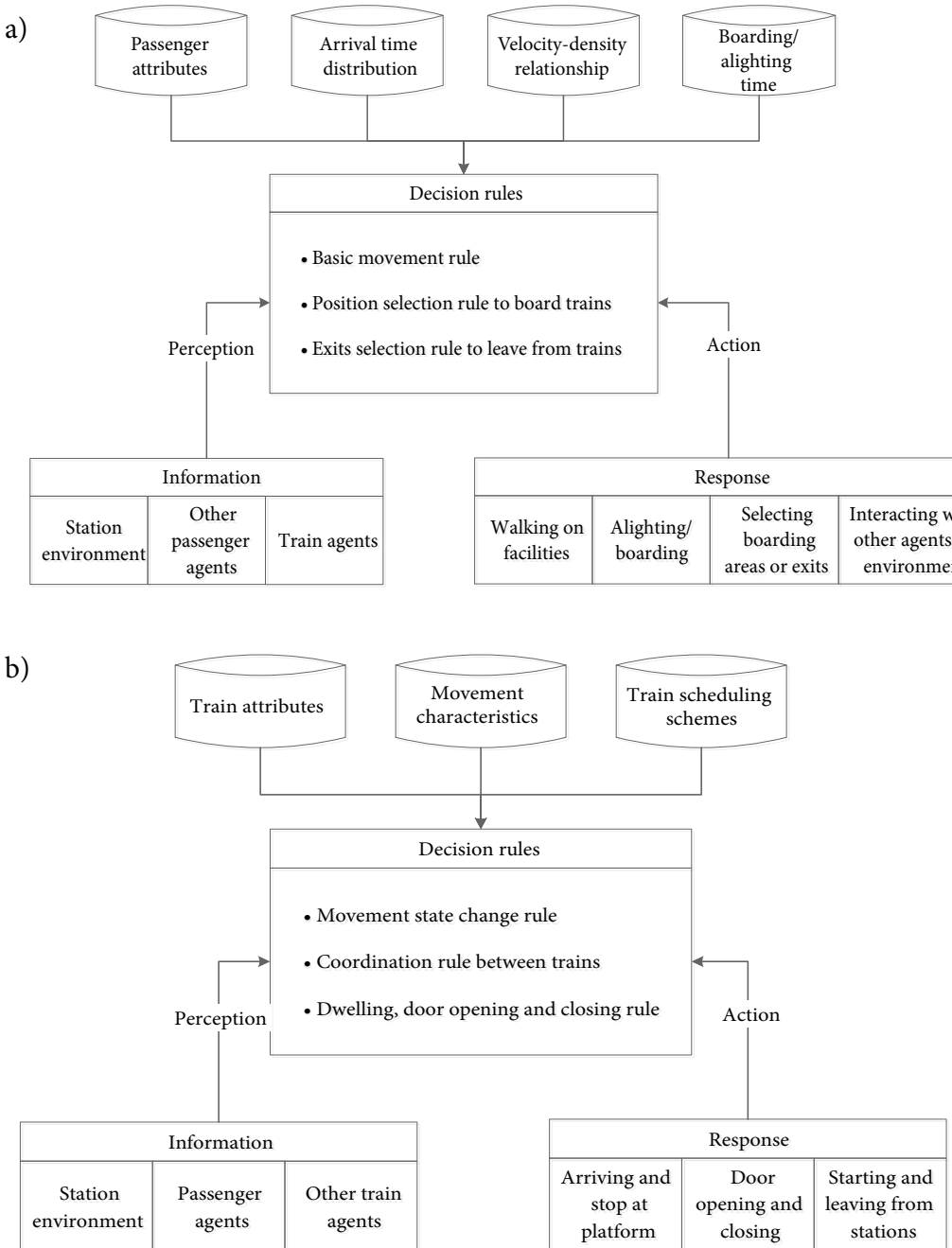

Figure 1. Framework of agents: $\mathrm{a}$ - passenger agent; $\mathrm{b}$ - train agents 
opening and closing doors as well as coordinating with other trains. The detailed framework of train agents is given in Figure $1 b$.

\subsubsection{Operational process of passenger-train agents system}

The decision and actions of passenger and train agents actually constitute a complete operational process, which can be divided into the inflow and outflow sections according to the movement direction of passengers. The former indicates how passenger agents are proceeding from the entrances to platforms for boarding trains. The latter demonstrates how passenger agents are leaving from trains and moving to exits.

Inflow process of passenger agents. The inflow process flowchart is described in Figure 2a. The passenger agents usually enter stations through entrances, walk on concourses and then arrive at platforms through stairways and escalators. The arrival time distribution of passengers calibrated from collecting field data has to be considered here. The passenger agents are required to determine their directions of movement and waiting areas boarding trains in the light of the position selection rule in Section 1.1. If train agents arrive with the given headways, passenger agents will board them within a boarding time, which excludes door opening and closing from dwelling time. The train agents depart for next stations while the inflow pro- cess is completed. The movement of passenger agents has to meet the relationship between the velocity and density of passengers.

Outflow process of passenger agents. The outflow process flowchart is characterized in Figure 2b. The passenger agents from last stations arrive at the current station and alight on platforms during the period between train agents opening and closing their doors. They select stairways or escalators to leave from the alighting area according to the exit selection rules given in Section 1.1. Similar to the inflow process before, the velocity-density relationship is employed to describe the movement of passenger agents.

The multi-agent simulation approach is proposed for these two processes through both aiming at the contents in the two dashed boxes in Figure 2 and combining the construction of environment. The above two processes are implemented using the AnyLogic in Figure 3.

\subsubsection{Flowchart of simulation}

The overall simulation flowchart and the contents described in the dashed boxes in Figure 2 are further provided in Figure 4. The passenger and train agents take actions according to their perception to the entities and events in environment as well as their decision rules. Their interactions, which are respectively shown in the lower left and right parts, are illustrated by two dashed lines and realized through the boarding and alighting processes.

a)

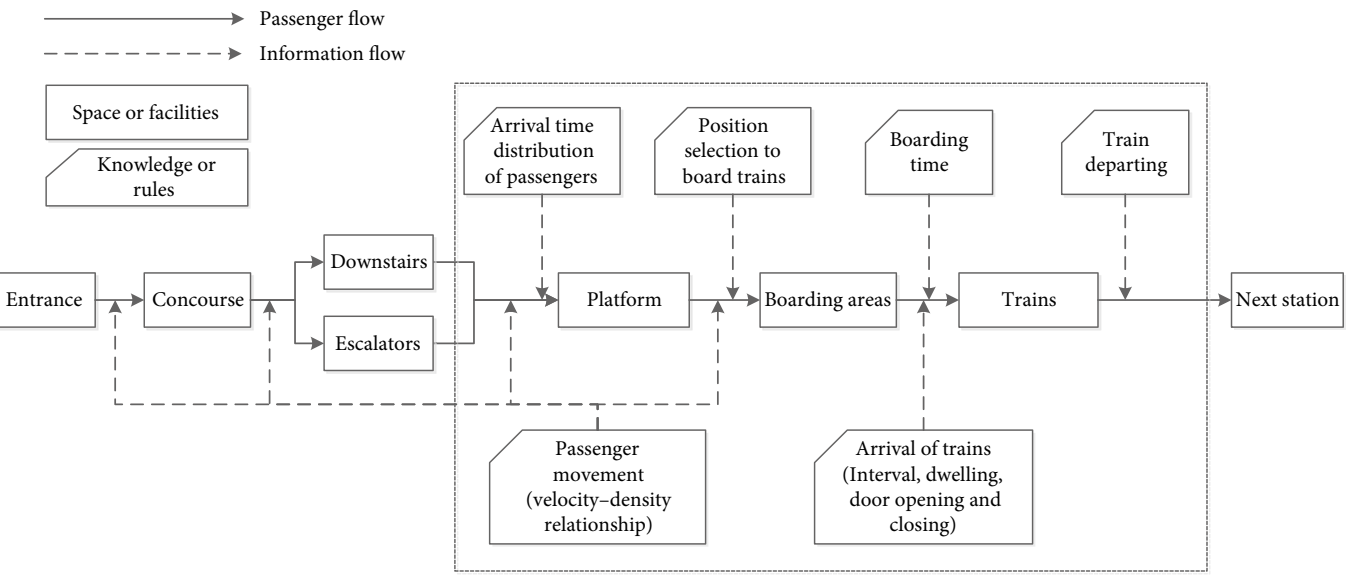

b)

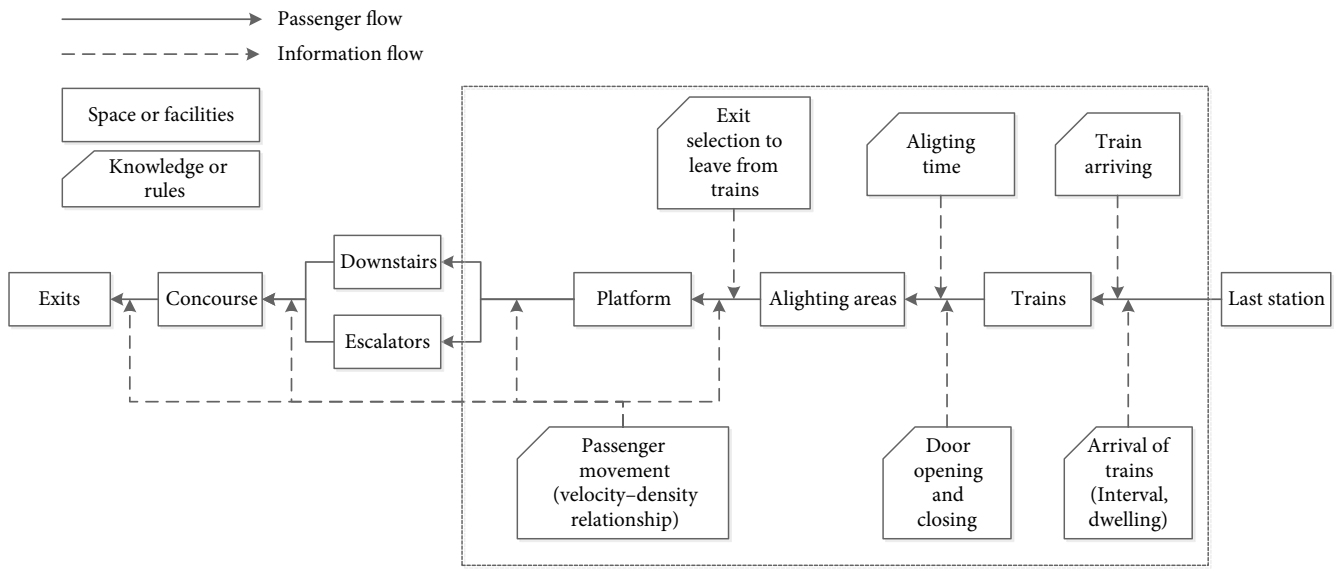

Figure 2. Movement process of passengers in metro stations: $a$ - inflow process; $b$ - outflow process 
a)
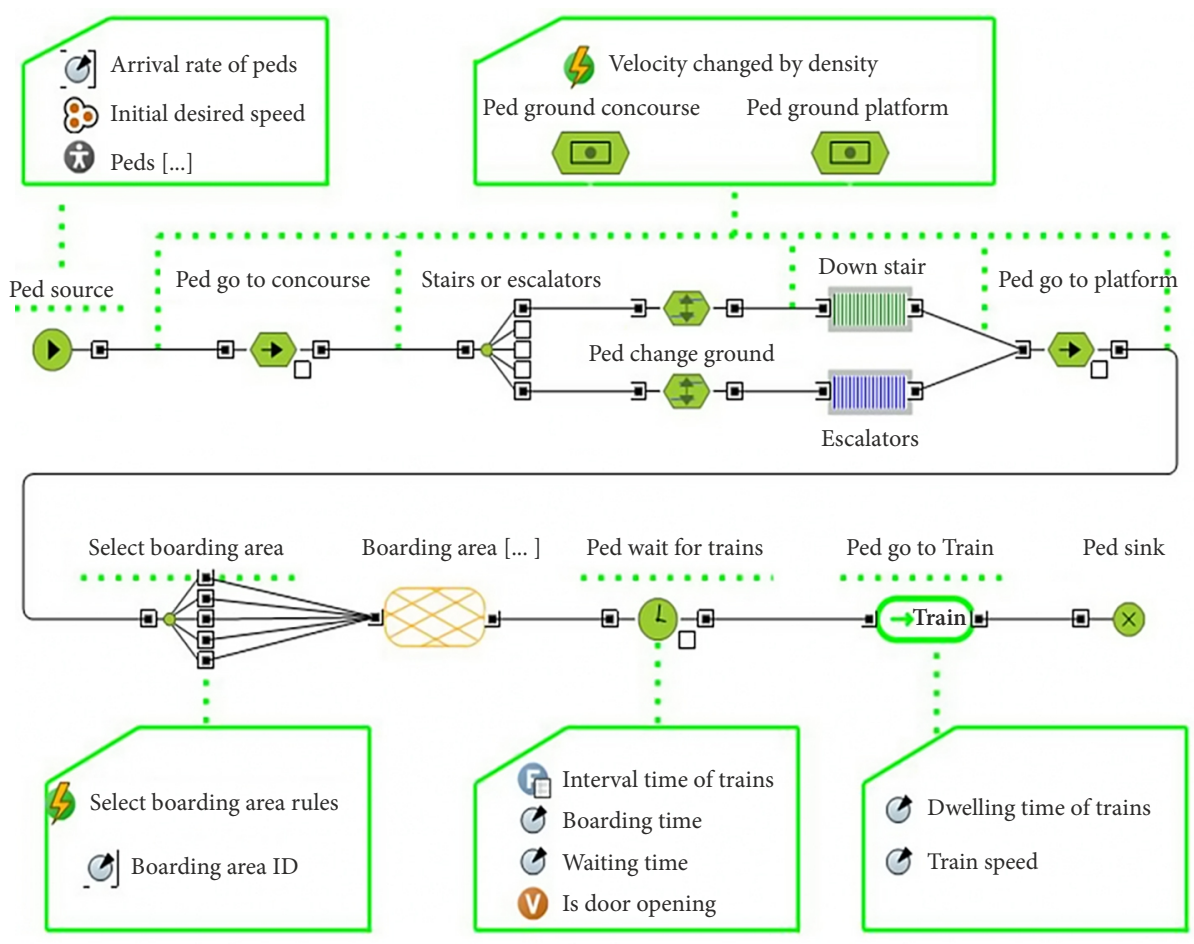

b)

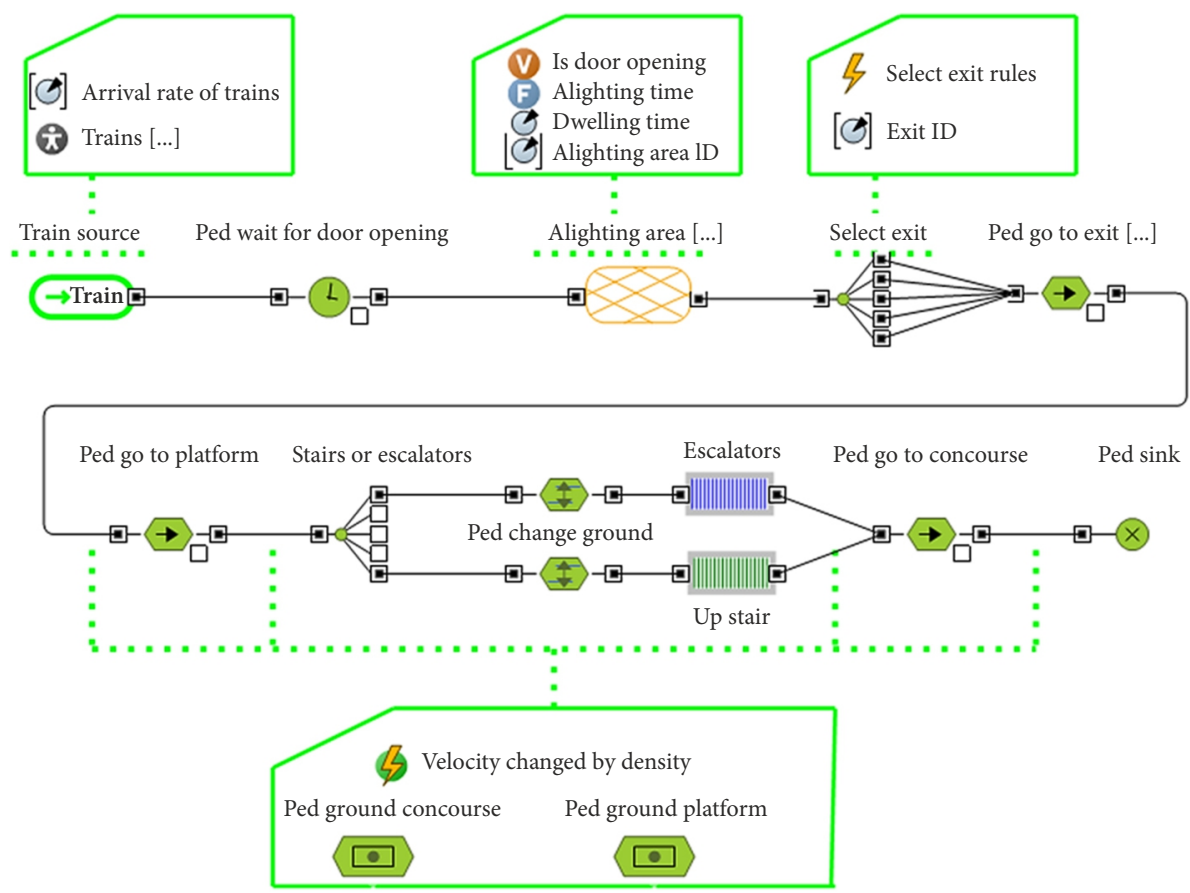

Figure 3. Modelling movement process of passengers through AnyLogic: $\mathrm{a}$ - inflow process; $\mathrm{b}$ - outflow process

The interaction between passenger movement and train operation given in Figure 4 is implemented by the AnyLogic in Figure 5. The boarding passengers moving from platforms are usually waiting and then enter trains while the alighting passengers from trains arrive on platforms and then join the leaving passengers. The interaction process is always repeated as long as passengers and trains constantly arrive on the platforms. 


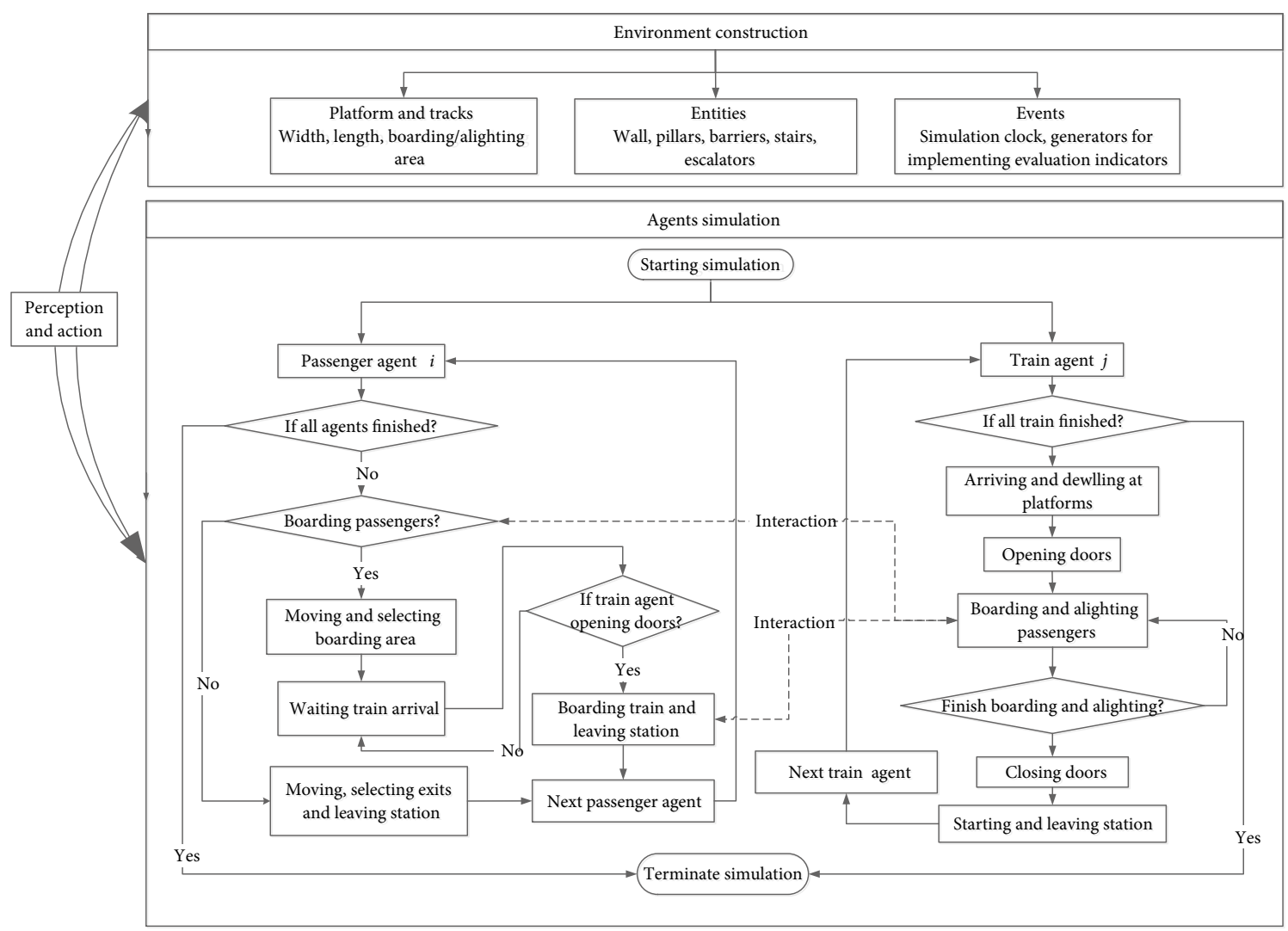

Figure 4. Simulation flowchart of the proposed multi-agent model

\begin{tabular}{|l|l|l|l|}
\hline Environment construction \\
Ped configuration
\end{tabular}

Figure 5. Modelling the interaction between passenger movement and train operation through AnyLogic

\section{Case studies}

\subsection{Setup}

The Hai-Dian-Huang-Zhuang (HDHZ) station, which is the interchange station of Lines 4 and 10 in the Beijing metro network is selected here for verifying the feasibility and effectiveness of the proposed method. The amount of transfer passengers through the HDHZ station is more than 164 thousand persons per day in 2014 so that its platforms are often overcrowded. The setup and parameter preparation for the case studies is carried out due to collected data before the implementation of evaluating the impacts from train operation on passenger flow. 


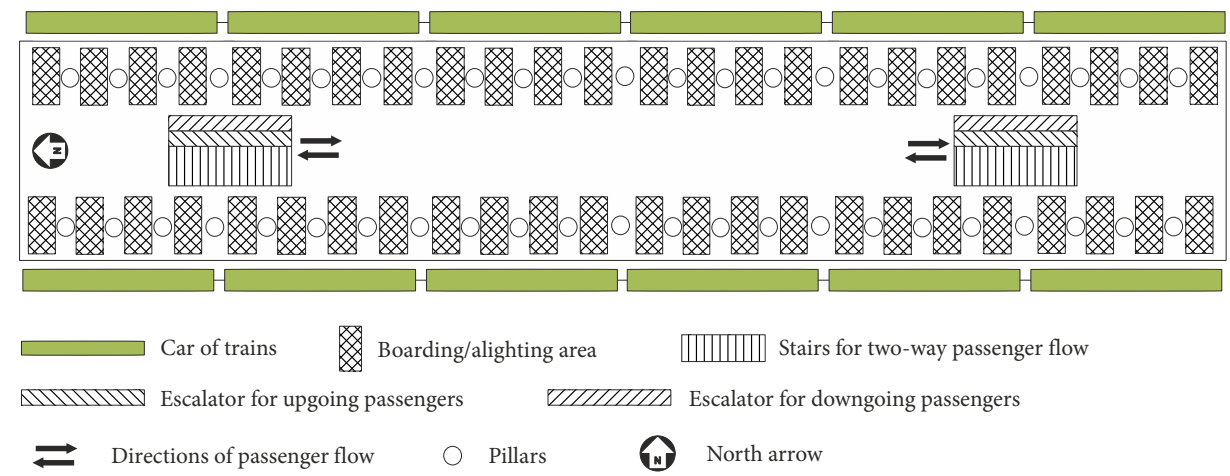

Figure 6. Geometry of the platform in the HDHZ station for the case studies

Geometry of platform. The platform serving for Line 4 in the HDHZ station is selected here, whose geometry is given in Figure 6. Its length and width are 112.5 and 13 meters respectively. There are totally two stairways (both directions) and four escalators (two up- and downdirection respectively) connecting the platform and twenty-four boarding/alighting areas where passengers will board or alight from the trains with six cars every several minutes. The stairways, escalators and platform (R1, R2 and R3) are considered as three different regions to evaluate passenger flow in the case studies.

The time distribution of passengers arriving on the platform for alighting trains yields to a Poisson distribution. The average arrival rate is about 14200 passengers (including all from stairways and escalators) per peak hour according to filed survey. The train headways usually vary from 120 to $180 \mathrm{~s}$ during peak hours and the minimum headways is $107 \mathrm{~s}$. The average differences of arrival time between up- and down-direction trains are about 60 and $82 \mathrm{~s}$. The average dwell time of trains is $38 \mathrm{~s}$.

Density-velocity relationship of passengers. The velocity of passengers usually varies with their density when they are walking. However, escalators are required to run at a nearly constant speed (GB 50157-2013). The relationship between density and velocity is able to be investigated through Equations (2) to (6). Six crucial parameters for line densities in these equations are obtained through a field survey in the HDHZ station, where $\rho_{1 c}, \rho_{2 c}, \rho_{1 m}, \rho_{2 m}$, $\rho_{1}^{*}$ and $\rho_{2}^{*}$ respectively equal to $0.67,1.0,2.6,1.43,1.64$ and 1.22 persons $/ \mathrm{m}$. The equations or value for the above relationship are calibrated due to the observed density and velocity and then summarized in Table 2 .

Table 2. Fitting results on the density-velocity relationship of passengers

\begin{tabular}{|l|l|c|}
\hline \multicolumn{1}{|c|}{ Positions } & \multicolumn{1}{c|}{ Passenger walking speed $[\mathrm{m} / \mathrm{s}]$} & $R$-square \\
\hline Platform & $v(\rho)=0.773-0.027 \cdot \ln (\rho)-0.107 \cdot \rho$ & 0.921 \\
\hline Upstairs & $v(\rho)=0.915-0.025 \cdot \ln (\rho)-0.205 \cdot \rho$ & 0.904 \\
\hline Downstairs & $v(\rho)=0.885-0.126 \cdot \ln (\rho)-0.137 \cdot \rho$ & 0.924 \\
\hline Escalators & 0.87 & - \\
\hline
\end{tabular}

Parameter calibration for the boarding area selection model. There are twenty four boarding areas to select for passengers from the platform entrances in the HDHZ station. The selection method given by Equation (7) is employed to calculate the probability of selection. The field data of passenger distribution between platform entrances and boarding areas $P_{i j}$ is very hard to be attained due to a great number of passengers and their complicated trajectories. Thus, Equation (7) has to be transformed into the other expression Equation (15). For any boarding area $i$, the total selection probability from all entrances (two platforms entrances totally here) $\sum_{j} P_{i j}$ are easily attained according to a field survey. A multiple linear regression method is engaged in calibrating the parameter $K_{i j}$ for the boarding area $i$ after Equation (15) is transformed using logarithm function:

$$
\sum_{j} P_{i j}=\sum_{j} K_{i j} \cdot \frac{\left(\rho_{i \max }-\rho_{i}\right) \cdot c_{j}}{d_{i j}^{2}} .
$$

Thirteen groups of filed data over different time periods on $\sum_{j} P_{i j}, \rho_{i \max }, \rho_{i}, d_{i j}$ and $c_{j}$ for the boarding area $i$ are collected and then calculated. The results on the calibrated parameter $K_{i j}$, including the values and their $R$ squares, are listed in Table 3.

Average time for boarding and alighting. The duration of passenger boarding or alighting is closely related to the operation of trains and number of passengers and usually calculated by Equation (8). The main parameters required are obtained through the investigation in the HDHZ station and their results are listed in Table 4.

The above work is imported as basic configurations into the multi-agent-based simulation approach proposed in Section 2. The further research and analysis combining train operations is carried out in the following sections.

\subsection{Simulation scenarios}

The simulation scenarios in the case studies are partitioned into three groups as listed in Table 5 according to the variances of train headways, differences of arrival time between up- and down-direction trains and dwell times of trains. 
Table 3. Calibration results of the parameters for the boarding area selection model

\begin{tabular}{|c|c|c|c|}
\hline No of areas $i$ & $K_{i j}, j=1$ & $K_{i j}, j=2$ & $R$-square \\
\hline 1 & 1.628 & 87.582 & 0.830 \\
\hline 2 & 1.713 & 47.702 & 0.845 \\
\hline 3 & 0.631 & 82.597 & 0.806 \\
\hline 4 & 0.515 & 50.288 & 0.826 \\
\hline 5 & 0.273 & 59.318 & 0.861 \\
\hline 6 & 0.289 & 33.695 & 0.852 \\
\hline 7 & 0.453 & 17.632 & 0.809 \\
\hline 8 & 1.411 & 2.346 & 0.898 \\
\hline 9 & 4.452 & 19.786 & 0.874 \\
\hline 10 & 5.057 & 7.753 & 0.856 \\
\hline 11 & 3.748 & 21.715 & 0.863 \\
\hline 12 & 8.318 & 5.359 & 0.926 \\
\hline 13 & 3.760 & 15.538 & 0.824 \\
\hline 14 & 5.592 & 7.878 & 0.833 \\
\hline 15 & 4.882 & 8.088 & 0.878 \\
\hline 16 & 9.596 & 2.880 & 0.852 \\
\hline 17 & 5.726 & 3.154 & 0.837 \\
\hline 18 & 8.445 & 1.470 & 0.872 \\
\hline 19 & 14.945 & 0.469 & 0.884 \\
\hline 20 & 16.217 & 0.405 & 0.875 \\
\hline 21 & 15.700 & 0.761 & 0.842 \\
\hline 22 & 17.756 & 1.474 & 0.870 \\
\hline 23 & 22.488 & 2.202 & 0.867 \\
\hline 24 & 22.170 & 3.978 & 0.864 \\
\hline
\end{tabular}

Table 4. Collected time-related parameters for the calculation of dwell time

\begin{tabular}{|l|c|c|}
\hline \multicolumn{1}{|c|}{ Terms } & Mean [s] & Standard deviation [s] \\
\hline $\begin{array}{l}\text { Boarding time } \\
\text { of passenger } t_{b d}\end{array}$ & 1.013 & 0.230 \\
\hline $\begin{array}{l}\text { Alighting time } \\
\text { of passenger } t_{a l}\end{array}$ & 0.984 & 0.202 \\
\hline $\begin{array}{l}\text { Door open and close } \\
\text { time } t_{\text {op-cl }}\end{array}$ & 2.25 & 0.311 \\
\hline $\begin{array}{l}\text { Arrival and departure } \\
\text { time of trains } t_{\text {arr-dep }}\end{array}$ & 5.95 & 0.724 \\
\hline
\end{tabular}

The first group involving eight cases (H1 to $\mathrm{H} 8$ ) focuses on the impacts due to different train headways from 90 to 240 s. The second group with five cases (DI1 to DI5) concentrates the influences from changing the differences of arrival time of between up- and down-direction trains under the five optimal train headways ( $\mathrm{H} 1, \mathrm{H} 3, \mathrm{H} 5, \mathrm{H} 7$, $\mathrm{H} 8$ ). The last group including 5 cases (DT1 to DT5) concerns the effects from various dwell times of trains considering the combinations of the optimal headways and differences of arrival time between trains $\left(\left(\mathrm{H} 1, \mathrm{DI} 1^{*}\right),(\mathrm{H} 3\right.$, D2 $\left.\left.1^{*}\right),\left(\mathrm{H} 5, \mathrm{DI} 3^{*}\right),\left(\mathrm{H} 7, \mathrm{DI} 4^{*}\right),\left(\mathrm{H} 8, \mathrm{DI} 5^{*}\right)\right)$.

\subsection{Results and analysis}

The above scenarios are carried out to analyse the impacts from train operations through the proposed multi-agentbased simulation approach. The detailed results due to the evaluation indicators given in Section 1.3 and corresponding analysis are summarized as below.

\subsubsection{Train headway}

Train headways have various impacts on passenger flow through the results in Table 6, which are obtained by eight simulation scenarios with different train headways.

The average densities of passengers within three regions (stairways, escalators and platform, i.e., R1, R2 and R3) show some dissimilarities when trains headways increase from 90 to $240 \mathrm{~s}$. The average density on stairways constantly becomes larger with train headways since the accumulation of in-flow passengers have a stronger impact on stairways than the evacuation of out-flow passengers; the average density through escalators oscillates irregularly as it is mainly related to the capacity of escalators and random arrival of passengers; the average density on the platform firstly decreases and then increase as many passengers on trains will frequently arrive in a short time if the headway is small while a large number of passenger will be waiting a longer time for trains if the headway is large.

The temporal equitabilities of passenger distribution exhibit the differences over time on the stairways, escalators and platform. It totally decreases on the stairways as train headways increase, which indicates that long train headways can allocate passengers more evenly there while the opposite situations occur on the escalators and platform.

Table 5. Simulation scenarios in the case studies when operation conditions vary

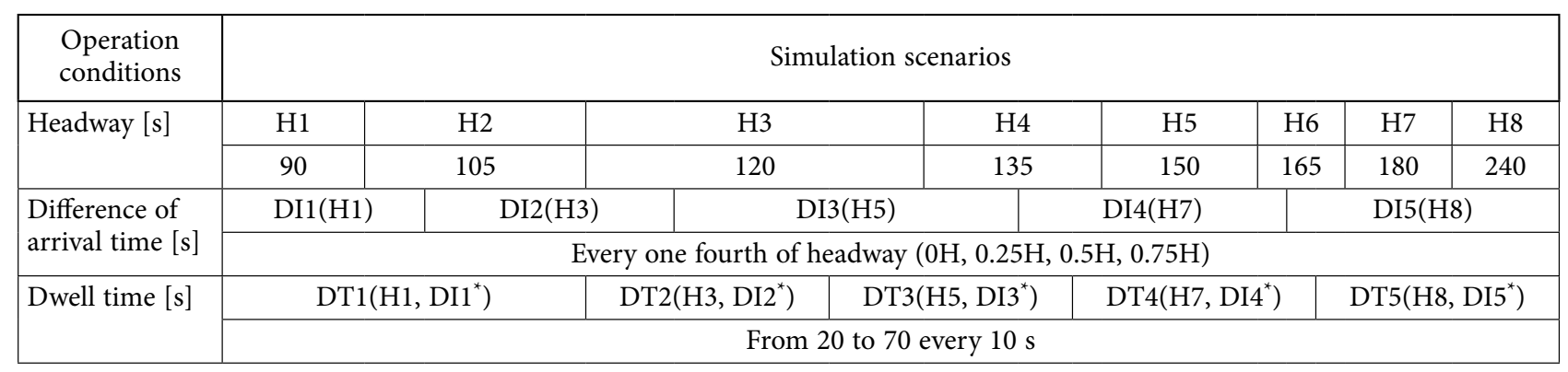

Note: ${ }^{*}$ indicates the recommend difference of train arrival time under a given headway. 
Table 6. Simulation results of eight scenarios with different train headways

\begin{tabular}{|c|c|c|c|c|c|c|c|c|c|}
\hline \multicolumn{2}{|c|}{ No. of Scenarios } & H1 & $\mathrm{H} 2$ & $\mathrm{H} 3$ & $\mathrm{H} 4$ & H5 & H6 & $\mathrm{H} 7$ & $\mathrm{H} 8$ \\
\hline \multirow{3}{*}{$\begin{array}{l}\text { Average density } \\
{\left[\text { person } / \mathrm{m}^{2}\right]}\end{array}$} & $\mathrm{R} 1$ & 2.27 & 2.44 & 2.48 & 2.67 & 2.65 & 2.81 & 2.90 & 3.01 \\
\hline & $\mathrm{R} 2$ & 1.77 & 1.67 & 1.59 & 1.87 & 1.90 & 1.86 & 1.78 & 1.14 \\
\hline & R3 & 1.87 & 1.80 & 1.61 & 1.65 & 1.67 & 1.57 & 1.60 & 1.78 \\
\hline \multirow{3}{*}{$\begin{array}{l}\text { Temporal } \\
\text { equitability }\end{array}$} & $\mathrm{R} 1$ & 1.71 & 1.64 & 1.66 & 1.69 & 1.63 & 1.63 & 1.65 & 1.59 \\
\hline & $\mathrm{R} 2$ & 1.75 & 1.79 & 1.81 & 1.86 & 1.93 & 2.03 & 2.07 & 2.41 \\
\hline & $\mathrm{R} 3$ & 1.50 & 1.52 & 1.59 & 1.64 & 1.76 & 1.79 & 1.81 & 1.88 \\
\hline \multicolumn{2}{|l|}{ Spatial equitability } & 1.97 & 2.03 & 2.05 & 2.08 & 2.09 & 2.2 & 2.21 & 2.42 \\
\hline \multirow{2}{*}{ Efficiency of movement } & $\mathrm{R} 1$ & 0.74 & 0.77 & 0.75 & 0.79 & 0.76 & 0.81 & 0.82 & 0.83 \\
\hline & R3 & 0.53 & 0.58 & 0.61 & 0.62 & 0.63 & 0.64 & 0.66 & 0.74 \\
\hline \multicolumn{2}{|c|}{ Average length of queue [person] } & 6.96 & 8.16 & 8.83 & 9.87 & 13.12 & 15.01 & 15.99 & 17.61 \\
\hline
\end{tabular}

The increasing spatial equitability with train headways reveals that a long train headway leads the unequally distribution of passengers in space among the stairways, escalators and platform.

The efficiencies of passengers moving on both the stairways and platform constantly descend when train headways are prolonged, especially on the platform where the incremental queue of passengers to board trains deteriorates the movement efficiency more obviously than on the stairways.

\subsubsection{Arrival time coordination between up and down trains}

The differences between the arrival times of trains in up and down directions obviously affect the passenger flow performance. The average density, temporal and spatial equitabilities, movement efficiency and average queue length through Scenarios DI1 to DI5 are given in Table 7 and Figure 7.

Table 7. Evaluation indicators considering difference of arrival time

\begin{tabular}{|c|c|c|c|c|c|c|}
\hline \multicolumn{3}{|c|}{ Difference of arrival time [s] } & $0 \mathrm{H}$ & $0.25 \mathrm{H}$ & $0.5 \mathrm{H}$ & $0.75 \mathrm{H}$ \\
\hline \multirow{15}{*}{ 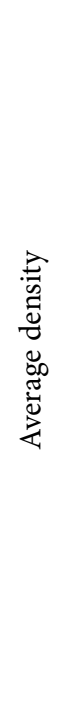 } & \multirow{3}{*}{ DI1 } & $\mathrm{R} 1$ & 2.28 & 2.34 & 2.15 & 2.27 \\
\hline & & R2 & 1.93 & 1.82 & 1.72 & 1.85 \\
\hline & & R3 & 1.64 & 1.59 & 1.54 & 1.58 \\
\hline & \multirow{3}{*}{ DI2 } & $\mathrm{R} 1$ & 2.73 & 2.68 & 2.51 & 2.64 \\
\hline & & $\mathrm{R} 2$ & 1.75 & 1.69 & 1.62 & 1.71 \\
\hline & & R3 & 1.72 & 1.64 & 1.57 & 1.63 \\
\hline & \multirow{3}{*}{ DI3 } & $\mathrm{R} 1$ & 2.82 & 2.77 & 2.67 & 2.74 \\
\hline & & $\mathrm{R} 2$ & 2.13 & 2.04 & 1.95 & 2.01 \\
\hline & & R3 & 1.72 & 1.69 & 1.62 & 1.67 \\
\hline & \multirow{3}{*}{ DI4 } & $\mathrm{R} 1$ & 2.78 & 2.96 & 2.86 & 3.06 \\
\hline & & $\mathrm{R} 2$ & 1.96 & 1.87 & 1.79 & 1.86 \\
\hline & & R3 & 1.70 & 1.64 & 1.61 & 1.65 \\
\hline & \multirow{3}{*}{ DI5 } & $\mathrm{R} 1$ & 2.80 & 2.74 & 2.70 & 2.77 \\
\hline & & $\mathrm{R} 2$ & 2.02 & 1.92 & 1.91 & 1.94 \\
\hline & & R3 & 2.51 & 2.43 & 2.39 & 2.45 \\
\hline
\end{tabular}

End of Table 7

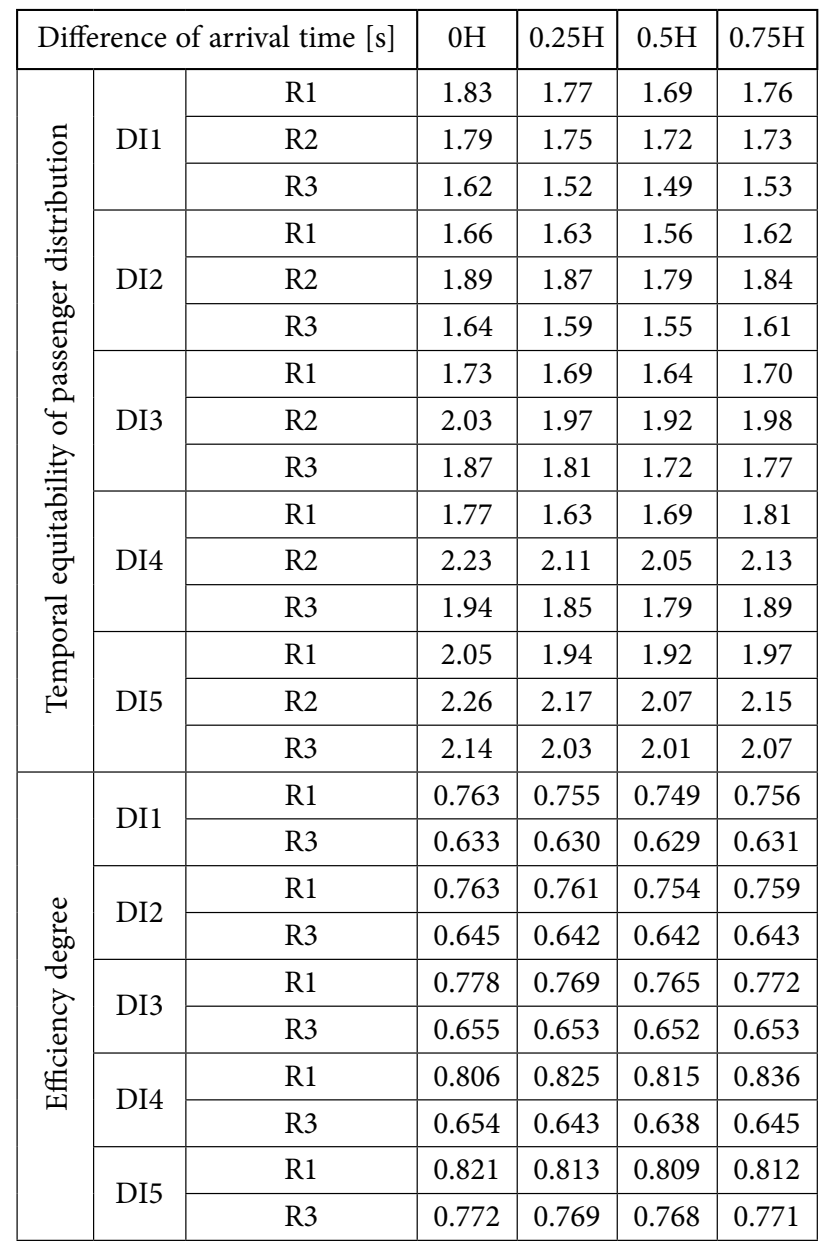

The average densities almost firstly decline and then increase with the difference of train arrival time from $\mathrm{Ta}$ ble 7, which reveals that the congestion level of passengers on the stairways, escalators and platform will approach the minimum if two trains in up and down directions arrive with a certain time interval that usually is about a half of train headways. The identical results on temporal and spatial equitabilities, movement efficiency and average queue length of passengers are obtained from Table 7 and Figure 7. 
a)

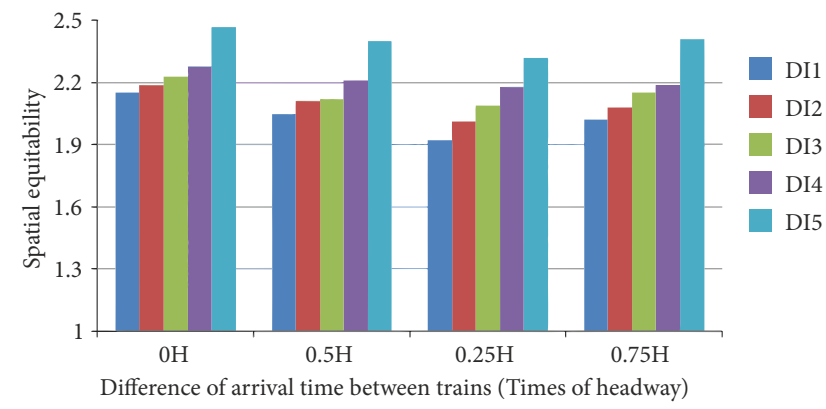

b)

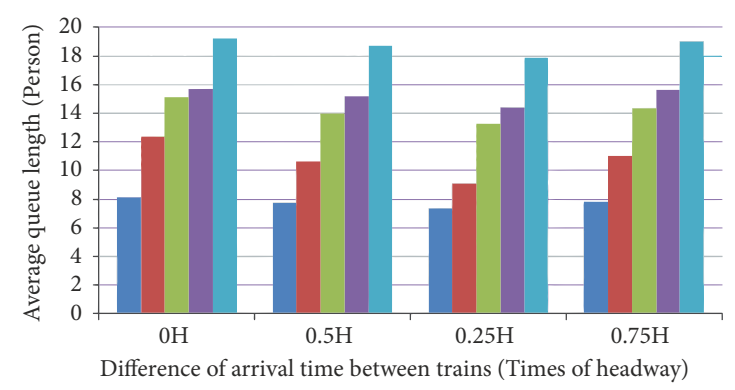

Figure 7. Spatial equitability (a) and average queue length (b) considering difference of arrival time

The operational performance of passenger flow will reach a maximum value if the differences of train arrival times between up and down directions can be kept closely to a half of train headways.

\subsubsection{Dwell time of trains}

The passenger flow performances considering the effects from the dwell times of trains, which vary from 20 to $70 \mathrm{~s}$ with an interval of $5 \mathrm{~s}$ are reported in Table 8 and Figure 8 through Scenarios DT1 to DT5 where the arrival intervals between up and down trains are approximately set to a half of train headways.

The average densities of passengers on the stairways and escalators oscillate with the dwell time of trains from Table 8 while the average density on the platform continuously descends when the dwell time increases. It indicates the passenger density on the platform is negatively related to dwell times.

The temporal equitabilities on the stairways and escalators have the similar treads as average densities. However, the temporal equitability on the platform has a lowest section of values, which shows that the corresponding sections of dwell time (highlighted by the digits in bold/ italic type in Table 8) are recommended to be employed for Scenarios DT1 to DT5.

The spatial equitabilities among the stairways, escalators and platform deliver some certain features for Scenarios DT1 to DT5. For any scenario, the spatial equitability always goes down firstly and then up in Figure 8a, which demonstrates that the optimal dwell time of trains will be situated from 30 to $60 \mathrm{~s}$. Furthermore, the optimal values a)

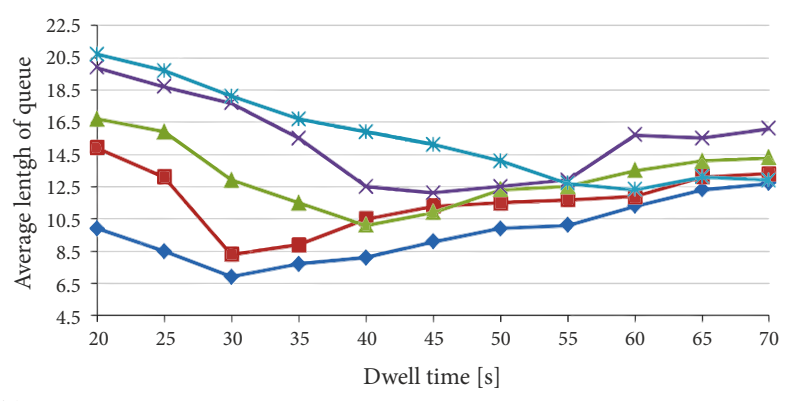

b)

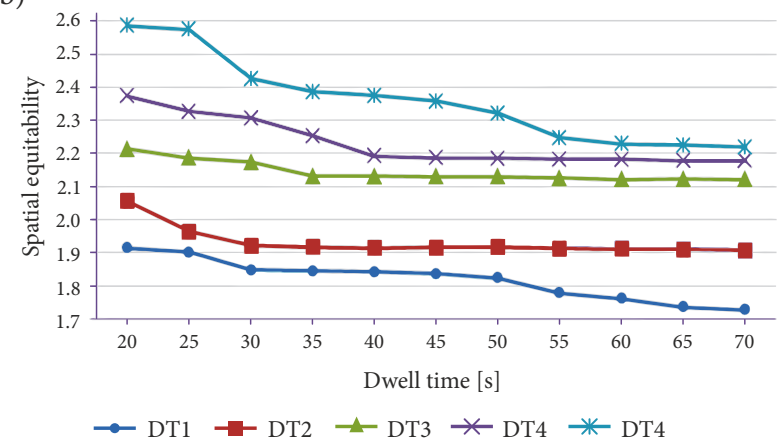

Figure 8. Spatial equitability (a) and average queue length (b) when the dwell time of trains varies

generally rise with the train headways in Scenarios DT1 to DT5.

The average length of passengers queuing within the boarding areas has a relatively simple changing trend with the dwell time of trains. It is always decreasing over the dwell time for the five scenarios DT1 to DT5.

The LOS of passengers on the stairways is designated into Level $\mathrm{F}$ while those on the escalators and platform are both identified between Level C and D in the case studies due to density. The LOS due to speed or efficiency on the stairways and platform are ascertained as Level F. The trends of temporal equitability among stairways, escalators and platform are quite complex, especially when train headways, differences between the arrival times of trains in up and down directions as well as dwell times of trains are changing. The temporal equitability on platform is generally the best if the train headway is small. However, the temporal equitability on escalators deteriorates the fastest with the increase of train headway.

\section{Conclusions}

The impacts analysis of train operation on passenger flow is a crucial component to ensure the low risk and high efficiency of operational management in metro stations. A multi-agent- based approach is developed and implemented in the study after addressing the impact factors including movement characteristics and train operation conditions and extracting the corresponding evaluation indicators. The case studies are performed to verify the effectiveness of the proposed approach based on actual traffic data. 
Table 8. Evaluation indicators when the dwell time of trains varies

\begin{tabular}{|c|c|c|c|c|c|c|c|c|c|c|c|c|c|}
\hline \multicolumn{3}{|c|}{ Dwell time [s] } & 20 & 25 & 30 & 35 & 40 & 45 & 50 & 55 & 60 & 65 & 70 \\
\hline \multirow{15}{*}{ 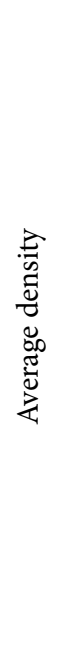 } & \multirow{3}{*}{ DT1 } & R1 & 2.24 & 2.39 & 2.44 & 2.31 & 2.33 & 2.19 & 2.27 & 2.35 & 2.48 & 2.21 & 2.20 \\
\hline & & $\mathrm{R} 2$ & 1.78 & 1.63 & 1.84 & 1.79 & 1.73 & 1.64 & 1.77 & 1.52 & 1.69 & 1.75 & 1.73 \\
\hline & & R3 & 1.79 & 1.71 & 1.6 & 1.58 & 1.59 & 1.56 & 1.53 & 1.48 & 1.43 & 1.39 & 1.36 \\
\hline & \multirow{3}{*}{ DT2 } & R1 & 2.62 & 2.51 & 2.48 & 2.56 & 2.71 & 2.63 & 2.47 & 2.81 & 2.56 & 2.43 & 2.42 \\
\hline & & R2 & 1.78 & 1.63 & 1.84 & 1.79 & 1.73 & 1.64 & 1.59 & 1.52 & 1.69 & 1.75 & 1.76 \\
\hline & & R3 & 1.84 & 1.77 & 1.63 & 1.61 & 1.56 & 1.57 & 1.57 & 1.53 & 1.5 & 1.47 & 1.45 \\
\hline & \multirow{3}{*}{ DT3 } & $\mathrm{R} 1$ & 2.67 & 2.91 & 2.92 & 2.89 & 2.72 & 2.77 & 2.61 & 2.74 & 2.81 & 2.66 & 2.69 \\
\hline & & $\mathrm{R} 2$ & 1.79 & 1.69 & 1.82 & 1.74 & 1.93 & 1.92 & 1.97 & 1.84 & 1.77 & 1.8 & 1.72 \\
\hline & & R3 & 2.29 & 2.13 & 2.05 & 1.83 & 1.64 & 1.62 & 1.6 & 1.59 & 1.62 & 1.62 & 1.62 \\
\hline & \multirow{3}{*}{ DT4 } & R1 & 2.93 & 2.74 & 2.69 & 2.96 & 2.87 & 2.89 & 2.67 & 2.85 & 2.99 & 2.69 & 2.70 \\
\hline & & R2 & 1.66 & 1.99 & 1.85 & 1.89 & 1.98 & 1.86 & 1.89 & 1.94 & 1.88 & 1.93 & 1.87 \\
\hline & & R3 & 2.36 & 2.17 & 1.99 & 1.89 & 1.73 & 1.69 & 1.68 & 1.68 & 1.66 & 1.67 & 1.65 \\
\hline & \multirow{3}{*}{ DT5 } & R1 & 2.98 & 2.87 & 2.84 & 2.47 & 2.91 & 2.69 & 2.71 & 2.88 & 2.9 & 2.73 & 2.79 \\
\hline & & R2 & 2.21 & 1.89 & 1.89 & 1.91 & 1.89 & 1.93 & 1.9 & 1.91 & 1.82 & 1.95 & 1.86 \\
\hline & & R3 & 2.77 & 2.71 & 2.64 & 2.66 & 2.51 & 2.42 & 2.37 & 2.12 & 1.94 & 1.91 & 1.87 \\
\hline \multirow{15}{*}{ 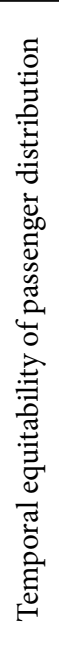 } & \multirow{3}{*}{ DT1 } & R1 & 1.74 & 1.55 & 1.59 & 1.62 & 1.79 & 1.69 & 1.71 & 1.69 & 1.58 & 1.73 & 1.67 \\
\hline & & R2 & 1.67 & 1.72 & 1.86 & 1.74 & 1.83 & 1.69 & 1.75 & 1.82 & 1.77 & 1.79 & 1.76 \\
\hline & & R3 & 1.58 & 1.49 & 1.41 & 1.42 & 1.49 & 1.48 & 1.51 & 1.56 & 1.59 & 1.64 & 1.66 \\
\hline & \multirow{3}{*}{ DT2 } & R1 & 1.69 & 1.65 & 1.57 & 1.62 & 1.53 & 1.57 & 1.55 & 1.66 & 1.62 & 1.51 & 1.59 \\
\hline & & R2 & 1.73 & 1.82 & 1.78 & 1.75 & 1.83 & 1.8 & 1.78 & 1.79 & 1.88 & 1.72 & 1.76 \\
\hline & & R3 & 1.61 & 1.58 & 1.46 & 1.47 & 1.5 & 1.53 & 1.56 & 1.59 & 1.62 & 1.67 & 1.67 \\
\hline & \multirow{3}{*}{ DT3 } & R1 & 1.93 & 1.64 & 1.72 & 1.91 & 1.82 & 1.66 & 1.63 & 1.74 & 1.92 & 1.69 & 1.72 \\
\hline & & R2 & 1.95 & 1.81 & 1.79 & 1.97 & 1.88 & 1.94 & 1.91 & 1.89 & 1.85 & 1.99 & 1.98 \\
\hline & & R3 & 1.99 & 1.93 & 1.85 & 1.73 & 1.72 & 1.69 & 1.75 & 1.77 & 1.82 & 1.79 & 1.84 \\
\hline & \multirow{3}{*}{ DT4 } & R1 & 1.92 & 1.95 & 2.1 & 1.59 & 1.64 & 1.76 & 1.56 & 1.89 & 2.03 & 1.78 & 1.89 \\
\hline & & R2 & 2.14 & 2.04 & 2.15 & 2.07 & 2.09 & 2.12 & 2.11 & 2.12 & 2.08 & 2.16 & 2.21 \\
\hline & & R3 & 1.98 & 2.06 & 2.16 & 1.99 & 1.84 & 1.81 & 1.83 & 2.19 & 2.21 & 2.31 & 2.37 \\
\hline & \multirow{3}{*}{ DT5 } & R1 & 1.76 & 1.88 & 1.8 & 1.92 & 1.69 & 2.1 & 1.92 & 1.83 & 2.01 & 1.89 & 1.82 \\
\hline & & R2 & 2.22 & 2.13 & 1.97 & 2.02 & 2.11 & 2.03 & 2.1 & 1.93 & 2.01 & 2.1 & 2.15 \\
\hline & & R3 & 2.43 & 2.39 & 2.31 & 2.29 & 2.09 & 2.02 & 1.99 & 1.91 & 1.9 & 2.11 & 2.19 \\
\hline \multirow{10}{*}{ 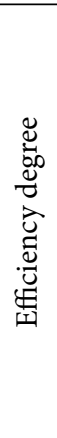 } & \multirow{2}{*}{ DT1 } & $\mathrm{R} 1$ & 0.734 & 0.726 & 0.723 & 0.747 & 0.744 & 0.761 & 0.745 & 0.762 & 0.759 & 0.749 & 0.766 \\
\hline & & R3 & 0.665 & 0.657 & 0.646 & 0.646 & 0.642 & 0.631 & 0.628 & 0.622 & 0.603 & 0.584 & 0.582 \\
\hline & \multirow{2}{*}{ DT2 } & $\mathrm{R} 1$ & 0.741 & 0.769 & 0.812 & 0.791 & 0.8 & 0.769 & 0.751 & 0.823 & 0.789 & 0.803 & 0.812 \\
\hline & & R3 & 0.693 & 0.689 & 0.651 & 0.646 & 0.639 & 0.643 & 0.641 & 0.623 & 0.611 & 0.6 & 0.597 \\
\hline & \multirow{2}{*}{ DT3 } & R1 & 0.761 & 0.789 & 0.821 & 0.814 & 0.807 & 0.784 & 0.763 & 0.816 & 0.774 & 0.806 & 0.791 \\
\hline & & R3 & 0.744 & 0.74 & 0.707 & 0.684 & 0.653 & 0.654 & 0.648 & 0.65 & 0.643 & 0.641 & 0.638 \\
\hline & \multirow{2}{*}{ DT4 } & R1 & 0.822 & 0.801 & 0.796 & 0.825 & 0.816 & 0.818 & 0.793 & 0.814 & 0.829 & 0.796 & 0.821 \\
\hline & & R3 & 0.756 & 0.73 & 0.703 & 0.687 & 0.65 & 0.653 & 0.651 & 0.651 & 0.647 & 0.649 & 0.643 \\
\hline & \multirow{2}{*}{ DT5 } & R1 & 0.798 & 0.832 & 0.802 & 0.788 & 0.821 & 0.811 & 0.799 & 0.823 & 0.805 & 0.791 & 0.815 \\
\hline & & R3 & 0.821 & 0.813 & 0.8 & 0.791 & 0.774 & 0.77 & 0.762 & 0.745 & 0.736 & 0.747 & 0.729 \\
\hline
\end{tabular}

Appropriate train operation conditions, like headways, differences between the arrival times of trains and dwell times, are pivotal for metro operators to improve operational performance. The methodology approach proposed here is helpful to identify recommended configurations of train operation conditions through evaluating the performance of passenger movement on platforms in metro stations. It is also able to be supportive to train scheduling issues through extending the investigation and analysis of passenger behaviours in future work.

\section{Funding}

This work was supported by the National Natural Science Foundation of China [grant number 71621001 and 71571015] and Beijing Natural Science Foundation [grant number 9152013].

\section{Disclosure statement}

The authors declare here that they have not any competing financial, professional, or personal interests from other parties. 


\section{References}

Chen, R.; Li, X.; Dong, L.-Y. 2012. Modeling and simulation of weaving pedestrian flow in subway stations, Acta Physica Sinica 61(14): 1-9. https://doi.org/10.7498/aps.61.144502 (in Chinese).

Chen, S.; Zhou, R.; Zhou, Y.; Mao, B. 2013. Computation on bus delay at stops in Beijing through statistical analysis, Mathematical Problems in Engineering 2013: 1-9. https://doi.org/10.1155/2013/745370

Fang, Z.; Lo, S. M.; Lu, J. A. 2003. On the relationship between crowd density and movement velocity, Fire Safety Journal 38(3): 271-283. https://doi.org/10.1016/S0379-7112(02)00058-9

Galland, S.; Knapen, L.; Yasar, A.-U.-H.; Gaud, N.; Janssens, D.; Lamotte, O.; Koukam, A.; Wets, G. 2014. Multi-agent simulation of individual mobility behavior in carpooling, Transportation Research Part C: Emerging Technologies 45: 83-98. https://doi.org/10.1016/j.trc.2013.12.012

GB 50157-2013. Code for Design of Metro. China National Standard. Standardization Administration of the People's Republic of China (in Chinese).

Guo, R.-Y. 2014. New insights into discretization effects in cellular automata models for pedestrian evacuation, Physica A: Statistical Mechanics and its Applications 400: 1-11. https://doi.org/10.1016/j.physa.2014.01.001

Helbing, D.; Buzna, L.; Johansson, A.; Werner, T. 2005. Selforganized pedestrian crowd dynamics: experiments, simulations, and design solutions, Transportation Science 39(1): 1-24. https://doi.org/10.1287/trsc.1040.0108

Helbing, D.; Johansson, A.; Mathiesen, J.; Jensen, M. H.; Hansen, A. 2006. Analytical approach to continuous and intermittent bottleneck flows, Physical Review Letters 97(16): 1-4. https://doi.org/10.1103/PhysRevLett.97.168001

Helbing, D.; Molnár, P. 1995. Social force model for pedestrian dynamics, Physical Review E 51(5): 4282-4286. https://doi.org/10.1103/PhysRevE.51.4282

Huo, F.; Song, W.; Lv, W.; Liew, K. M. 2014. Analyzing pedestrian merging flow on a floor-stair interface using an extended lattice gas model, Simulation: Transactions of the Society for Modeling and Simulation International 90(5): 501-510. https://doi.org/10.1177/0037549714526294

Jiang, C. S.; Yuan, F.; Chow, W. K. 2010. Effect of varying two key parameters in simulating evacuation for subway stations in China, Safety Science 48(4): 445-451. https://doi.org/10.1016/j.ssci.2009.12.004

Jiang, Y.; Hu, L.; Zhu, J.; Chen, Y. 2013. PH fitting of the arrival interval distribution of the passenger flow on urban rail transit stations, Applied Mathematics and Computation 225: 158-170. https://doi.org/10.1016/j.amc.2013.09.005

Kosonen, I. 2003. Multi-agent fuzzy signal control based on realtime simulation, Transportation Research Part C: Emerging Technologies 11(5): 389-403.

https://doi.org/10.1016/S0968-090X(03)00032-9

Lam, W. H. K.; Cheung, C.-Y.; Lam, C. F. 1999. A study of crowding effects at the Hong Kong light rail transit stations, Transportation Research Part A: Policy and Practice 33(5): 401-415. https://doi.org/10.1016/S0965-8564(98)00050-0

Liu, S.; Lo, S.; Ma, J.; Wang, W. 2014. An agent-based microscopic pedestrian flow simulation model for pedestrian traffic problems, IEEE Transactions on Intelligent Transportation Systems 15(3): 992-1001. https://doi.org/10.1109/TITS.2013.2292526
Miyoshi, T.; Nakayasu, H.; Ueno, Y.; Patterson, P. 2012. An emergency aircraft evacuation simulation considering passenger emotions, Computers \& Industrial Engineering 62(3): 746-754. https://doi.org/10.1016/j.cie.2011.11.012

National Academies of Sciences, Engineering, and Medicine. 2013. Transit Capacity and Quality of Service Manual. 3rd edition. Washington, DC, US: The National Academies Press. 685 p. https://doi.org/10.17226/24766

Niazi, M.; Hussain, A. 2011. Agent-based computing from multiagent systems to agent-based models: a visual survey, Scientometrics 89(2): 479-499.

https://doi.org/10.1007/s11192-011-0468-9

Niu, H.; Zhou, X. 2013. Optimizing urban rail timetable under time-dependent demand and oversaturated conditions, Transportation Research Part C: Emerging Technologies 36: 212-230. https://doi.org/10.1016/j.trc.2013.08.016

Qu, L.; Chow, W. K. 2012. Platform screen doors on emergency evacuation in underground railway stations, Tunnelling and Underground Space Technology 30: 1-9.

https://doi.org/10.1016/j.tust.2011.09.003

Ren, G.; Zhao, X.; Li, Y. 2014. Route optimization model for pedestrian evacuation in metro hubs, Journal of Central South University 21(2): 822-831.

https://doi.org/10.1007/s11771-014-2006-4

Shi, C.; Zhong, M.; Nong, X.; He, L.; Shi, J.; Feng, G. 2012. Modeling and safety strategy of passenger evacuation in a metro station in China, Safety Science 50(5): 1319-1332. https://doi.org/10.1016/j.ssci.2010.07.017

Wan, J.; Sui, J.; Yu, H. 2014. Research on evacuation in the subway station in China based on the combined social force model, Physica A: Statistical Mechanics and its Applications 394: 33-46. https://doi.org/10.1016/j.physa.2013.09.060

Wong, R. C. W.; Yuen, T. W. Y.; Fung, K. W.; Leung, J. M. Y. 2008. Optimizing timetable synchronization for rail mass transit, Transportation Science 42(1): 57-69. https://doi.org/10.1287/trsc.1070.0200

Wu, G.-Y.; Chien, S.-W.; Huang, Y.-T. 2010. Modeling the occupant evacuation of the mass rapid transit station using the control volume model, Building and Environment 45(10): 2280-2288. https://doi.org/10.1016/j.buildenv.2010.04.015

Zhang, X.; Li, X.; Hadjisophocleous, G. 2013. A probabilistic occupant evacuation model for fire emergencies using Monte Carlo methods, Fire Safety Journal 58: 15-24. https://doi.org/10.1016/j.firesaf.2013.01.028

Zhang, J.; Seyfried, A. 2014. Comparison of intersecting pedestrian flows based on experiments, Physica A: Statistical Mechanics and its Applications 405: 316-325. https://doi.org/10.1016/j.physa.2014.03.004

Zhong, M.; Shi, C.; Tu, X.; Fu, T.; He, L. 2008. Study of the human evacuation simulation of metro fire safety analysis in China, Journal of Loss Prevention in the Process Industries 21(3): 287-298. https://doi.org/10.1016/j.jlp.2007.08.001 